Revue bibliographique pour le domaine irano-aryen

\title{
Mahdokht Farjamirad. Mortuary Practice in Ancient Iran from the Achaemenid to the Sasanian Period
}

\section{Samra Azarnouche}

\section{(2) OpenEdition}

1 Journals

\section{Édition électronique}

URL : http://journals.openedition.org/abstractairanica/45615

DOI : 10.4000/abstractairanica.45615

ISBN : 1961-960X

ISSN : 1961-960X

Éditeur :

CNRS (UMR 7528 Mondes iraniens et indiens), Éditions de l'IFRI

Référence électronique

Samra Azarnouche, "Mahdokht Farjamirad. Mortuary Practice in Ancient Iran from the Achaemenid to the Sasanian Period ", Abstracta Iranica [En ligne], Volume 37-38-39|2018, document 55, mis en ligne le 30 décembre 2018, consulté le 26 septembre 2020. URL : http://journals.openedition.org/ abstractairanica/45615 ; DOI : https://doi.org/10.4000/abstractairanica.45615

Ce document a été généré automatiquement le 26 septembre 2020

Tous droits réservés 


\title{
Mahdokht Farjamirad. Mortuary Practice in Ancient Iran from the Achaemenid to the Sasanian Period
}

\author{
Samra Azarnouche
}

\section{RÉFÉRENCE}

Mahdokht Farjamirad. Mortuary Practice in Ancient Iran from the Achaemenid to the Sasanian Period. Oxford: Archaeopress, 2015, 396 p., figures, tableaux, plans, bibliographies, (BAR International Series 2747)

1 Cet impressionnant catalogue des monuments funéraires de l'Iran préislamique correspond à une version légèrement modifiée d'une thèse soutenue à Gand en 2014 (dir. E. Haerinck), dont plusieurs chapitres traitant des sources textuelles ont été mis de côté («Textual evidence on burial rituals ", "Interface between textual evidence and archaeological reality ", et le dossier des inscriptions funéraires), pour se limiter au matériel archéologique. Très bref (p. 3-33), le commentaire se divise en quatre chapitres chronologiques (périodes achéménide, post-achéménide et séleucide, parthe et sassanide) composés chacun de deux parties, les sépultures en pleine terre ou en fosses rupestres et les monuments funéraires placés au-dessus du sol. La seconde partie de l'ouvrage comporte le catalogue à proprement parler, soit une fiche descriptive synthétique par monument (lieu, fouilles, type, mesures, orientation, disposition et conservation des restes humains, présence d'objets ou d'inscription, bibliographie, env. 200 pages au total), puis suivent les illustrations (photos, schémas, dessins, plans, modélisation 3D) dont certaines de l'A.

2 Pour la période sassanide, certaines parties ont fait l'objet d'articles indépendants, notamment celle sur les niches rupestres en périphérie des villes sassanides (voir notice Farjamirad 2015a), ou à propos des ossuaires sur colonnes récemment découverts (Do Gur-e Dopā). 
3 Le commentaire sur la terminologie (daxmag, astodān), présent dans la thèse, aurait pu être publié ici et élargi à ašwar. Une allusion aux rites funéraires aurait permis de mieux cerner le principe du décharnement des corps, qui peut être naturel (Bušehr, Liyān) ou résulté de l'exposition aux prédateurs (préconisations zoroastriennes, par ex. : « Le corps doit être exposé en hauteur, sur une montagne découverte ; il doit être attaché de manière à ce que les chiens et les oiseaux ne le déplacent pas vers des zones irriguées, cultivées ou habitées. Puis l'on doit porter les os dans un ossuaire placé audessus du sol et qui est recouvert d'un toit afin que ni l'eau ni les chiens ni les renards ne puissent y pénétrer. Il faut perforer un trou pour l'entrée de la lumière. L'ossuaire doit être taillé dans un monolithe, ainsi que son couvercle, que l'on pourvoira d'un trou. Pierres et plâtre doivent être disposés tout autour ", Dādestān i dènig 16.13, 17.2-4).

4 La supposée rigidité des pratiques funéraires zoroastriennes (p. 25) est mise à mal par les résultats même de cette enquête qui montre, d'une part, la présence d'inhumation à l'époque sassanide et, d'autre part, l'usage très circonscrit des niches rupestres et des ossuaires. Cette discordance entre théorie et pratique s'observe aussi dans d'autres contextes, comme les pratiques alimentaires où certaines viandes très prisées à la cour sassanide figurent parmi des tabous strictement fixés par les prêtres. Depuis la parution de Sh. Shaked, Dualism in Transformation. Varieties of Religion in Sasanian Iran, Londres, 1994 une approche plus nuancée des conceptions zoroastriennes est de rigueur.

5 A verser au dossier: M. Rahbar, «An Underground Elimaean Tomb at Saaleh Davood ", Nāmvarnāmeh. Papers in Honour of Massoud Azarnoush, H. Fahimi and K. Alizadeh, eds., Tehran, Iran Negar, 2012, p. 289-351.

6 Ces remarques n'enlèvent rien à la qualité de présentation et d'organisation de la matière de cet ouvrage, notamment par les tableaux synthétiques des données pour chaque sépulture, ainsi que de fort utiles cartes chronologiques indiquant la répartition des différents types d'aménagements funéraires. La mise en ligne d'une base de données serait à encourager.

\section{AUTEURS}

\section{SAMRA AZARNOUCHE}

EPHE, Mondes iranien et indien, Paris 